\title{
Micropropagation of Grewia tenax (Forssk.) Fiori - an important ethnomedicinal plant
}

\author{
Hussien M. Daffalla ${ }^{1 *}$, Azza M. Elsheikh ${ }^{1}$, Hiba A. Ali ${ }^{1}$, Mutasim M. Khalafalla ${ }^{2}$ \\ ${ }^{1}$ Commission for Biotechnology and Genetic Engineering, National Center for Research, Khartoum, Sudan \\ ${ }^{2}$ College of Public Health and Health Informatics, Umm AL-Qura University, Makkah, Saudi Arabia
}

\begin{abstract}
Grewia tenax (Forssk.) Fiori is a multi-purpose shrub species that is threatened in its natural environment because of extensive fruit collection and seed dormancy. We induced direct multiple shoots of $G$. tenax from the cotyledonary node, shoot, and stem node explants. The explants were cultured on a Murashige and Skoog (MS) solid medium supplemented with up to $4.0 \mathrm{mg} / \mathrm{l}$ of benzyladenine (BA), kinetin (Kin), isopentanyl adenine (2iP), or thidiazuron (TDZ). The highest number of shoots $(4.8 \pm 0.4)$ was obtained when 2 -shoot explants regenerated on the primary medium containing $3.0 \mathrm{mg} / 12 \mathrm{iP}$ were subcultured onto a secondary medium containing $1.0 \mathrm{mg} / \mathrm{l}$ BA. The induced-microshoots were transferred to either $1 / 4,1 / 2$, or full MS medium strengths. The use of a $1 / 4$ strength MS medium resulted in the formation of the highest number of roots and root length compared to a $1 / 2$ and full-strength MS. To improve rooting performance, indole-3-butyric acid (IBA) in various concentrations (up to $1.0 \mathrm{mg} / \mathrm{l})$ was provided to a $1 / 4$-strength $\mathrm{MS}$ medium. The average longest root $(3.2 \pm 0.4 \mathrm{~cm})$ was achieved on a medium supplemented with $0.2 \mathrm{mg} / \mathrm{l} \mathrm{IBA}$. A rooting frequency of $100 \%$ and the maximum number of roots $(6 \pm 1.5)$ per explant were obtained using $1 / 4$-strength MS medium containing $1.0 \mathrm{mg} / 1 \mathrm{IBA}$, and in vitro plantlets were successfully acclimatized with a $75 \%$ survival rate. This study provides an efficient in vitro propagation system for $G$. tenax.
\end{abstract}

Key words: Grewia tenax, multiple shoot induction, two-step culture procedure

\section{Introduction}

Grewia tenax (Forssk.) Fiori (Malvaceae) is a multistemmed deciduous shrub having a height of up to $3 \mathrm{~m}$ (Sharma and Patni, 2012). It predominantly occurs in the driest savannas and grows in clay as well as in sand at the desert margins and on rocky hills slopes in both semi-arid and sub-humid tropical climates (Gebauer et al., 2007; Aboagarib et al., 2015). The presence of G. tenax in the semiarid savanna, such as those in Sudan, makes it an essential plant species for the local population (Gebauer et al., 2007). It has become a prime component of a nutritious diet and a local substitute for vitamin pills, obtained from fruits, particularly during a time of food shortage (El Tahir and Gebauer, 2004). Typically, $G$. tenax is an inclusive nutraceutical plant that delivers biologically active constituents. Analysis of
G. tenax fruits indicated the presence of substantial amounts of iron (10-20 mg/100 g) and high carbohydrate contents (52-87\%) (Elhassan and Yagi, 2010; Aboagarib et al., 2015); therefore, eating its fruits helps to cure iron-deficiency anemia and other diseases. Moreover, extracts from different parts of this plant were used to cure various other ailments such as trachoma, tonsillitis, pulmonary infections, jaundice, rheumatism, and asthma; besides, they are used as a poultice to treat swellings (El Ghazali et al., 1997; Khemis et al., 2006). However, fruits of $G$. tenax may be commercially used for producing beverages, yogurts, ice creams, and baby food (Aboagarib et al., 2015). Furthermore, the cultivation of $G$. tenax is one of the primary sources of income for rural populations in Sudan and India (Gebauer et al., 2007; Sharma and Patni, 2012).

\footnotetext{
* Corresponding author: Plant Cell and Tissue Culture, Commission for Biotechnology and Genetic Engineering, Mohamed Nageeb, 1111, Khartoum, Sudan; e-mail: hdaffalla@yahoo.com
} 
G. tenax is considered to be one of the most affected fruit tree exposed to the deterioration of vegetation cover in Sudan due to increasing human activities (El Tahir and Gebauer 2004). Because of the extensive utilization of fruits, low viability and poor germination of seeds, and a lack of a plantation program, genetic resources of $G$. tenax are getting exhausted. Furthermore, $G$. tenax has been neglected by researchers and forest services for a long time, and there is very little information available on its propagation and early seedling establishment (Gebauer et al., 2007); thus, the shrub is being grown only via natural regeneration. Therefore, the Higher Council for Environment and Natural Resources, Sudan, considered this shrub as a threatened species (HCENR, 2000). In general, the poor germination of $G$. tenax seeds is caused by physical dormancy caused by a hard seed coat impermeable to water or resistant to radicle penetration. In addition the germination of $G$. tenax seeds was found to be affected by physiological dormancy, which is thought to be gradually declining over time after seed collection. Older seeds such as those obtained one year after collection have a better germination rate than fresh ones or those obtained after 2, 4, and 7 months after collection (Sahoo and Kasera, 2012; Saleem et al., 2012). Therefore, to overcome the dormancy seeds of $G$. tenax, a scarification pretreatment is required to make the seed coat absorptive to water and hasten germination (Sharma and Patni, 2012). Different scarification methods have been applied to improve the germination rate of $G$. tenax seeds. For instance, treating the seeds with ammonium nitrate resulted in a $46.7 \%$ germination rate (Sahoo and Kasera, 2012); however, exposing the seeds to a constant heat of $40^{\circ} \mathrm{C}$ for a duration of four weeks resulted in a $70 \%$ rate (Sohail et al., 2015). In fact, $77 \%$ of germination was achieved after treatment with ethrel for $24 \mathrm{~h}$ (Kumawat et al., 2017 ), and $93 \%$ of germination was achieved with hot water pretreatment (Saleem et al., 2012). Moreover, $G$. tenax seeds pretreated with sulfuric acid germinated with $80 \%$ efficiency (Ali and Abd Alla, 2003) and with $100 \%$ efficiency when the seeds were cultured in the dark (Daffalla et al., 2016).

Several studies on the propagation of $G$. tenax were performed using in vivo and in vitro methods. The conventional propagation of $G$. tenax was achieved through stem cuttings with variable results. Note that the maximum rooting percentage of $28.3 \%$ was achieved without the addition of auxins (Elkhalifa and Mahmoud, 1999), whereas the maximum rooting percentage of $77 \%$ (Ali and Abd Alla, 2003) and 61\% (El-Siddig et al., 2005) was achieved using IBA. The in vitro regeneration of $G$. tenax was reported in a few research studies (Ali and Abd Alla, 2003; Daffalla et al., 2016) in which only one shoot per nodal explant after treatment with cytokinins was produced.

For maintaining its population, in vitro regeneration techniques for the clonal propagation and in vitro conservation of this important species are useful. Based on the assumption that young tissues respond more easily to in vitro conditions than older trees, seedlings were preferred as a source of explants, as reported for Acacia senegal (Khalafalla and Daffalla, 2008). The aim of this study was to establish an efficient and reproducible micropropagation system for $G$. tenax, which is an important ethnomedicinal shrub.

\section{Material and methods}

\section{Basal medium and culture conditions}

Murashige and Skoog (1962) medium (MS) supplemented with $3 \%$ sucrose and a $\mathrm{pH}$ of 5.8 was solidified with $0.8 \%$ agar $(\mathrm{w} / \mathrm{v})$ before autoclaving at $121^{\circ} \mathrm{C}$ and $0.11 \mathrm{MPa}$ for $15 \mathrm{~min}$. The plant cultures were incubated at $25 \pm 2{ }^{\circ} \mathrm{C}$ under light $\left(50 \mu \mathrm{mol} \cdot \mathrm{m}^{-2} \cdot \mathrm{s}^{-1}\right.$ photosynthetic photon flux density) from a cool fluorescent light for $16 \mathrm{~h}$ a day.

\section{In vitro seed germination and explants preparation}

G. tenax seeds were pre-surface sterilized in $70 \%$ $(\mathrm{v} / \mathrm{v})$ ethanol for $30 \mathrm{~s}$ and rinsed three times in sterile distilled water. Then, the seeds were rinsed in $20 \%(\mathrm{v} / \mathrm{v})$ Clorox (commercial bleach, $5.25 \%$ sodium hypochlorite) for $15 \mathrm{~min}$ and thoroughly rinsed in sterile distilled water. Two disinfected seeds were inoculated per $100 \mathrm{ml}$ test tube $(20 \times 4 \mathrm{~cm})$ containing $15 \mathrm{ml}$ half-strength MS medium and kept in dark until germination. From the in vitro germinated seedlings, we prepared three types of explants. We prepared cotyledonary node $(\mathrm{CN})$ and shoot explants (SEs) having a length of $4-5 \mathrm{~cm}$ above the medium surface from 5-day-old seedlings. $\mathrm{CN}$ included both cotyledons with $\sim 1.0 \mathrm{~cm}$ of the hypocotyl, whereas SE included an epicotyl and an apex with the first true leaf $(0.5-1.0 \mathrm{~cm})$. Half of the hypocotyl and radicle were discarded with special care to ensure that 
the cotyledonous portion was not damaged. For preparing the stem node (SN) explants, 14-day-old seedlings $(8-10 \mathrm{~cm})$ were transversely cut into segments $(0.8$ $-1.0 \mathrm{~cm}$ ), each of which contained one bud.

\section{Inoculation of explants and shoot multiplication}

Three types of explants, namely, CN, SE, and SN, were cultured in an MS medium supplemented with benzyladenine (BA), kinetin (Kin), isopentanyl adenine (2iP), or thidiazuron (TDZ) at $0.0,0.5,1.0,2.0,3.0$, or $4.0 \mathrm{mg} / 1$. Note that two explants were cultured in a glass bottle $(8 \times 5 \mathrm{~cm}, 200 \mathrm{ml})$ containing $30 \mathrm{ml}$ of MS medium. For optimizing multiplication and proliferation, the clusters of the obtained shoots were subsequently sub-cultured four weeks later into the same but fresh medium.

To improve shoot multiplication, we developed a twostep culture system, which began with shoot induction on the primary medium supplemented with the optimal cytokinin concentration. The second step was to reculture the induced shoots on the proliferation medium containing $\mathrm{BA}$ at a wide range of concentrations $(0.0$ $-3.0 \mathrm{mg} / \mathrm{l})$. The propagation parameters in terms of a number of axillary shoots developed per explants, shoot length, and the number of nodes per shoot were recorded after four weeks of culturing. Each induced microshoots (shoot $>2 \mathrm{~cm}$ long, bared leaves and aged 4 weeks) was recorded, whereas smaller shoots were not counted. Furthermore, the percentage and incidence of rooting and callus at the base of explants on the multiplication medium were monitored.

\section{In vitro rooting and acclimatization}

After four weeks of culturing on the shoot induction medium, shoots (2-4 cm length) with 5-10 expanded leaves were cultured onto the rooting media. We served different strengths of MS medium for in vitro root induction, namely, 1/4-, 1/2-, and full-strength MS. After four weeks of culturing, percentage rooting, the number of roots, and root length per explant were obtained.

All culture bottles containing healthy rooted plantlets of $G$. tenax were transferred from the incubation room to growth room for hardening at temperatures ranging between 26 and $29^{\circ} \mathrm{C}$ with mild sunlight for two days. The plantlets were then removed, washed gently under running water and cultured into plastic pots $(5 \times 7 \mathrm{~cm})$ filled with sterilized mixture of silt: sand $(1: 1 ; \mathrm{v} / \mathrm{v})$ soil.
To maintain relative humidity around the plants, each pot was covered with a glass vessel. The pots were kept at room temperature and irrigated whenever soil surface was dried. After 2-3 weeks, the pots were uncovered but left under the same conditions until growth improved, e.g., the development of a new leaf (for two weeks). To examine their ex vitro acclimatization, the plantlets were then transferred into polyethylene bags (15 $\times 25 \mathrm{~cm}$ ) filled with the same mixture of soil and maintained in a greenhouse with required care.

\section{Experimental design and statistical analysis}

The experiments were set up as factorial experiments in a completely randomized design and repeated twice. We applied shoot induction and multiplication treatments in nine replicates. The in vitro rooting of microshoots was applied in six replicates, and the data were subjected to one-way or two-way analysis of variance (ANOVA). The mean separation was performed using Duncan's Multiple Range test (DMRT) at the 5\% level using Microsoft Excel.

\section{Results and discussion}

\section{Multiple shoots induction}

The SN, the SE, and the CN explants responded to cytokinins application in different ways. The type of explant, as well as cytokinin and its concentration, with a highly significant interaction $(P<0.001)$, influenced the frequency of multiple shoot formation (Table 1, Fig. 1).

The cultured SE explants did not produce any new shoots and the shoot tips only elongated. Unlike the results obtained in this study, Ishii and Kambou (2007) reported that the best explants in terms of the number of shoots induced were terminal leafy nodes (representing SE explant) compared to other studied explants of in vitro grown seedlings of Adansonia digitata (Malvaceae).

$\mathrm{CN}$ explants formed significantly $(P<0.05)$ the highest number of shoots $(2.8 \pm 0.2)$ that on $3.0 \mathrm{mg} / 12 \mathrm{iP}$ containing medium compared to $(2.5 \pm 0.19$ and 2.0 \pm 0.31 ) stimulated by $2.0 \mathrm{mg} / 1 \mathrm{BA}$ and $2.0 \mathrm{mg} / 1 \mathrm{Kin}$ (respectively), and $(0.8 \pm 0.1)$ by the control (Table 1$)$. Note that TDZ concentrations of 0.5 and $1.0 \mathrm{mg} / 1$ supported shoot differentiation from $\mathrm{CN}(1.3 \pm 0.2)$, whereas higher TDZ concentrations at 3.0 and $4.0 \mathrm{mg} / 1$ significantly decreased the average number of shoots to $0.5 \pm 0.2$ and $0.3 \pm 0.2$, respectively. 
Table 1. Effect of different cytokinins on the number of shoots ( $\geq 2 \mathrm{~cm}$ length) formed by $G$. tenax explants after four weeks of in vitro culturing

\begin{tabular}{|c|c|c|c|c|c|}
\hline \multirow{2}{*}{\multicolumn{2}{|c|}{$\begin{array}{l}\text { Cytokinin } \\
{[\mathrm{mg} / \mathrm{l}]}\end{array}$}} & \multicolumn{2}{|c|}{ Explants types* } & \multicolumn{2}{|c|}{$\begin{array}{c}\text { Intervention } \\
\text { of callus and root }\end{array}$} \\
\hline & & \multirow{2}{*}{$\frac{\mathrm{SN}}{1.0 \pm 0.00^{\mathrm{d}}}$} & \multirow{2}{*}{$\frac{\mathrm{CN}}{0.8 \pm 0.11^{\mathrm{e}}}$} & \multirow{2}{*}{$\begin{array}{c}\text { Callus } \\
\text { index }\end{array}$} & \multirow{2}{*}{$\begin{array}{c}\begin{array}{c}\text { Rooting } \\
{[\%]}\end{array} \\
50\end{array}$} \\
\hline & 0 & & & & \\
\hline \multirow[t]{5}{*}{$\mathrm{BA}$} & 0.5 & $0.8 \pm 0.11^{\mathrm{e}}$ & $1.8 \pm 0.18^{\mathrm{bc}}$ & $(-)$ & 40 \\
\hline & 1 & $0.8 \pm 0.11^{\mathrm{e}}$ & $2.2 \pm 0.08^{\mathrm{bc}}$ & $(-)$ & 25 \\
\hline & 2 & $0.7 \pm 0.14^{\mathrm{f}}$ & $2.5 \pm 0.19^{a}$ & $(++)$ & 10 \\
\hline & 3 & $0.7 \pm 0.14^{f}$ & $1.2 \pm 0.44^{\mathrm{cd}}$ & $(++)$ & 10 \\
\hline & 4 & $0.6 \pm 0.13^{f}$ & $1.5 \pm 0.26^{\mathrm{cd}}$ & $(+++)$ & 5 \\
\hline \multirow[t]{5}{*}{ Kin } & 0.5 & $0.8 \pm 0.08^{f}$ & $1.7 \pm 0.19^{c}$ & $(+)$ & 10 \\
\hline & 1 & $0.9 \pm 0.08^{\mathrm{e}}$ & $1.8 \pm 0.13^{\mathrm{bc}}$ & $(+)$ & 10 \\
\hline & 2 & $0.9 \pm 0.08^{d}$ & $2.0 \pm 0.31^{\mathrm{bc}}$ & $(+)$ & 10 \\
\hline & 3 & $1.0 \pm 0.00^{\mathrm{d}}$ & $1.8 \pm 0.17^{\mathrm{bc}}$ & $(+)$ & 10 \\
\hline & 4 & $0.9 \pm 0.09^{d}$ & $1.5 \pm 0.54^{\text {cd }}$ & $(++)$ & 5 \\
\hline \multirow[t]{5}{*}{$2 \mathrm{iP}$} & 0.5 & $1.0 \pm 0.00^{\mathrm{d}}$ & $1.7 \pm 0.14^{\mathrm{c}}$ & $(-)$ & 0 \\
\hline & 1 & $1.0 \pm 0.08^{\mathrm{d}}$ & $1.8 \pm 0.13^{\mathrm{bc}}$ & $(+)$ & 0 \\
\hline & 2 & $1.0 \pm 0.08^{\mathrm{d}}$ & $1.8 \pm 0.11^{\mathrm{bc}}$ & $(+)$ & 0 \\
\hline & 3 & $1.0 \pm 0.08^{d}$ & $2.8 \pm 0.21^{\mathrm{a}}$ & $(++)$ & 0 \\
\hline & 4 & $1.0 \pm 0.00^{\mathrm{d}}$ & $2.3 \pm 0.28^{b}$ & $(++)$ & 0 \\
\hline \multirow[t]{5}{*}{$\mathrm{TDZ}$} & 0.5 & $1.0 \pm 0.00^{\mathrm{d}}$ & $1.3 \pm 0.19^{\mathrm{cd}}$ & $(+)$ & 0 \\
\hline & 1 & $1.0 \pm 0.08^{\mathrm{d}}$ & $1.3 \pm 0.22^{\mathrm{cd}}$ & $(+)$ & 0 \\
\hline & 2 & $1.0 \pm 0.11^{\mathrm{d}}$ & $0.8 \pm 0.21^{\mathrm{e}}$ & $(++)$ & 0 \\
\hline & 3 & $0.8 \pm 0.11^{\mathrm{e}}$ & $0.5 \pm 0.15^{g}$ & $(++)$ & 0 \\
\hline & 4 & $0.8 \pm 0.13^{\mathrm{e}}$ & $0.3 \pm 0.15^{h}$ & $(+++)$ & 0 \\
\hline
\end{tabular}

Values are expressed as mean \pm standard error of nine replicates; means followed by different superscript letter are significantly different based on DMRT $(P=0.05)$; * - SE explant was not included as no axillary shoot was produced, $\mathrm{SN}$ - stem node, $\mathrm{CN}-$ cotyledonary node, Callus formation $(-)-$ no callus, $(+)-$ small, $(++)-$ medium, $(+++)$ - large

SN explants showed a weak response to cytokinin treatments in terms of the number of shoots formed (Table 1). All the tested cytokinins either facilitated the formation of only one shoot per node (the same as in control) or no shoots (Fig. 1A). BA at $4.0 \mathrm{mg} / \mathrm{l}$ induced the production of the lowest number of shoots $(0.6$ \pm 0.13 ) on SN explants. Moreover, the development of single shoots on nodal explants on cytokinin-supplemented media was reported with two-nodal explants of G. tenax (Ali and Abd Alla, 2003) and for single node explants of Grewia asiatica (Biswas et al., 2005).
The superiority of CNs in micropropagation has also been reported for other tree species such as Acacia senegal (Khalafalla and Daffalla, 2008) and Clitoria ternatea (Mukhtar et al., 2012). The better response of $\mathrm{CN}$ explants towards cytokinin treatments (Fig. 1B-F) may be because of the presence of expanded cotyledons as reported in Mukhtar et al. (2012), polysaccharides stored in cell walls may be degraded and mobilized to the developing shoots, thus enhancing their growth.

$2 \mathrm{iP}$ was found to be better than the other tested cytokinins for the multiple shoot induction from $G$. tenax ex- 

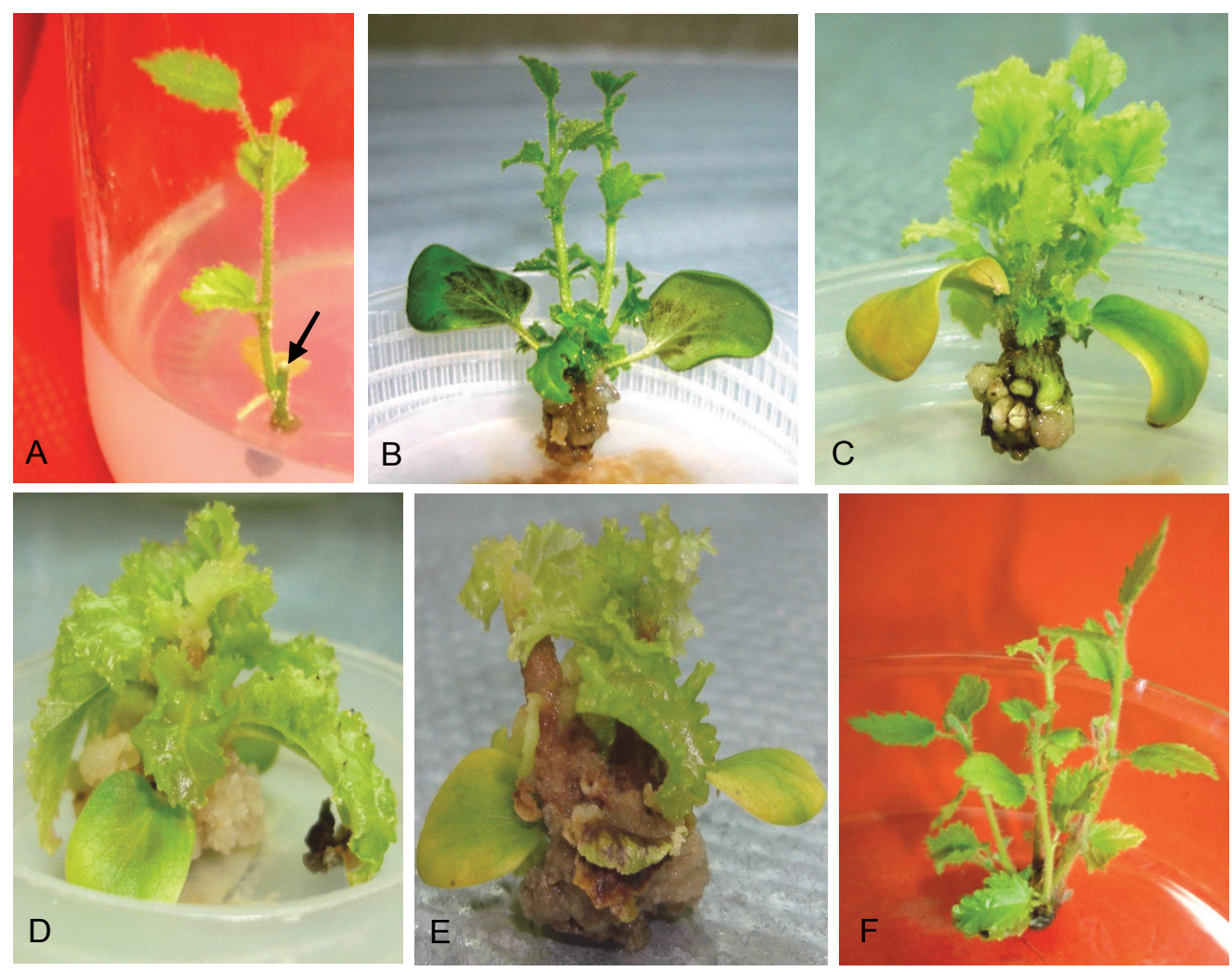

Fig. 1. Shoots multiplication of $G$. tenax after four weeks in culture; A) only one shoot from SN explant (arrow pointed cut end); and (B-F) from CN explants; B) long shoots in 0.5-2.0 mg/l of BA, Kin, and 2iP; C) short shoots in 2.0-3.0 mg/1 of BA and Kin; D) stunted shoots with callus in $4.0 \mathrm{mg}$ of BA, Kin, and 2iP; E) callus preventing multiplication in $3.0 \mathrm{mg} / 1 \mathrm{TDZ}$; and F) multiple shoots induction in $3.0 \mathrm{mg} / \mathrm{l} 2 \mathrm{iP}$

plants (Table 1). 2iP and Kin stimulated a lesser callus production on explants compared to BA and TDZ. Similarly, $2 \mathrm{iP}$ and TDZ did not stimulate root induction as observed in BA and Kin cultures. Sometimes, a particular cytokinin was required for promoting direct adventitious shoot formation, e.g., in Browallia viscosa, $2 \mathrm{iP}$ was required but Kin, BA, and zeatin were ineffective (Van Staden et al., 2008). The development of calli and roots can compete with axillary meristems in nutrition absorption, thus compromising shoot multiplication. Moreover, callus formation during micropropagation stage may obstruct the development of vascular connections linking shoots to roots at subsequent stages when subcultured for rooting. Furthermore, excessive callusing hindering shoot induction was reported in previous studies on G. tenax (Ali and Abd Alla, 2003; Daffalla et al., 2016) and $G$. asiatica (Biswas et al., 2005). The superiority of 2iP over other cytokinins for multiple shoot induction has been observed for several woody plant species such as Bixa orellana (Joseph et al., 2011) and Sophora tonkinensis (Jana et al., 2013).
The type of explants significantly $(P<0.05)$ affected the length of induced microshoots (Table 2, Fig. 1 ). The highest shoot length observed $(2.7 \pm 0.5 \mathrm{~cm})$ was recorded for $\mathrm{CN}$ explant cultured on a medium supplemented with $4.0 \mathrm{mg} / 12 \mathrm{iP}$. Note that $\mathrm{SN}$ explants produced the second average value of shoot length $(2.3 \mathrm{~cm})$ for both $2.0 \mathrm{mg} / 1 \mathrm{BA}$ and $0.5 \mathrm{mg} / \mathrm{l} 2 \mathrm{iP}$. This value did not significantly differ from that recorded for SE explants $(2 \mathrm{~cm})$ cultured on a medium supplemented with $0.5 \mathrm{mg} / 1 \mathrm{BA}$. However, the value of shoot length recorded for SE explants was for epicotyl elongation, and not for new shoots. A similar result was observed for the multiplication of Acacia senegal using a stem segment and $\mathrm{CN}$ explants (Khalafalla and Daffalla, 2008). However, 2iP was the most effective cytokinin for the elongation of $G$. tenax shoots followed by Kin, BA, and TDZ (Table 2). Furthermore, a similar ranking for the four cytokinins was reported for Sophora tonkinensis (Jana et al., 2013). The effectiveness of $2 \mathrm{iP}$ over BA for provoking longest shoots was observed for Bixa orellana (Joseph et al., 2011). Parveen and Shahzad (2010) indicated that cul- 
Table 2. Effect of different cytokinins on shoot length $(\mathrm{cm})$ of $G$. tenax explants after four weeks of in vitro culture

\begin{tabular}{|c|c|c|c|c|}
\hline \multirow{2}{*}{\multicolumn{2}{|c|}{$\begin{array}{c}\text { Cytokinin } \\
{[\mathrm{mg} / \mathrm{l}]}\end{array}$}} & \multicolumn{3}{|c|}{ Explants types } \\
\hline & & \multirow{2}{*}{$\frac{\mathrm{SN}}{1.8 \pm 029^{\mathrm{ab}}}$} & \multirow{2}{*}{$\frac{\mathrm{CN}}{0.7 \pm 0.31^{\mathrm{b}}}$} & \multirow{2}{*}{$\frac{\mathrm{SE}}{1.1 \pm 0.06}$} \\
\hline & 0.0 & & & \\
\hline \multirow[t]{5}{*}{ BA } & 0.5 & $1.8 \pm 0.4^{\mathrm{ab}}$ & $2.1 \pm 0.04^{\mathrm{ab}}$ & $2.0 \pm 0.05^{\mathrm{ab}}$ \\
\hline & 1.0 & $1.8 \pm 0.4^{\mathrm{ab}}$ & $2.1 \pm 0.04^{\mathrm{ab}}$ & $1.4 \pm 0.04^{\mathrm{ab}}$ \\
\hline & 2.0 & $2.3 \pm 0.34^{\mathrm{ab}}$ & $2.3 \pm 0.07^{\mathrm{ab}}$ & $1.4 \pm 0.24^{\mathrm{ab}}$ \\
\hline & 3.0 & $1.5 \pm 0.36^{\mathrm{ab}}$ & $2.0 \pm 0.21^{\mathrm{ab}}$ & $1.3 \pm 0.23^{\mathrm{ab}}$ \\
\hline & 4.0 & $0.7 \pm 0.28^{b}$ & $0.9 \pm 0.40^{\mathrm{b}}$ & $1.3 \pm 0.22^{\mathrm{ab}}$ \\
\hline \multirow[t]{5}{*}{ Kin } & 0.5 & $1.4 \pm 0.30^{\mathrm{ab}}$ & $2.4 \pm 0.07^{\mathrm{ab}}$ & $1.4 \pm 0.35^{\mathrm{ab}}$ \\
\hline & 1.0 & $2.0 \pm 0.42^{\mathrm{ab}}$ & $2.3 \pm 0.11^{\mathrm{ab}}$ & $1.5 \pm 0.26^{\mathrm{ab}}$ \\
\hline & 2.0 & $1.8 \pm 0.41^{\mathrm{ab}}$ & $2.3 \pm 0.24^{\mathrm{ab}}$ & $1.6 \pm 0.16^{\mathrm{ab}}$ \\
\hline & 3.0 & $1.7 \pm 0.57^{\mathrm{ab}}$ & $2.1 \pm 0.41^{\mathrm{ab}}$ & $1.6 \pm 0.18^{\mathrm{ab}}$ \\
\hline & 4.0 & $1.0 \pm 0.46^{\mathrm{b}}$ & $2.0 \pm 0.34^{\mathrm{ab}}$ & $2.0 \pm 0.26^{\mathrm{ab}}$ \\
\hline \multirow[t]{5}{*}{$2 \mathrm{iP}$} & 0.5 & $2.3 \pm 0.20^{\mathrm{ab}}$ & $2.3 \pm 0.08^{\mathrm{ab}}$ & $1.1 \pm 0.10^{b}$ \\
\hline & 1.0 & $2.1 \pm 0.28^{\mathrm{ab}}$ & $2.3 \pm 0.23^{\mathrm{ab}}$ & $1.2 \pm 0.16^{\mathrm{ab}}$ \\
\hline & 2.0 & $2.0 \pm 0.18^{\mathrm{ab}}$ & $2.4 \pm 0.26^{\mathrm{ab}}$ & $1.1 \pm 0.19^{b}$ \\
\hline & 3.0 & $1.6 \pm 0.28^{\mathrm{ab}}$ & $2.5 \pm 0.38^{\mathrm{ab}}$ & $1.0 \pm 0.07^{b}$ \\
\hline & 4.0 & $1.0 \pm 0.35^{b}$ & $2.7 \pm 0.53^{\mathrm{a}}$ & $0.9 \pm 0.05^{b}$ \\
\hline \multirow[t]{5}{*}{$\mathrm{TDZ}$} & 0.5 & $1.7 \pm 0.33^{\mathrm{ab}}$ & $2.0 \pm 0.28^{\mathrm{ab}}$ & $0.6 \pm 0.06^{\mathrm{b}}$ \\
\hline & 1.0 & $1.0 \pm 0.32^{\mathrm{b}}$ & $1.8 \pm 0.27^{\mathrm{ab}}$ & $0.6 \pm 0.05^{\mathrm{b}}$ \\
\hline & 2.0 & $1.2 \pm 0.33^{b}$ & $1.4 \pm 0.34^{\mathrm{ab}}$ & $0.3 \pm 0.14^{b}$ \\
\hline & 3.0 & $0.7 \pm 0.32^{b}$ & $1.0 \pm 0.30^{b}$ & $0.3 \pm 0.15^{b}$ \\
\hline & 4.0 & $0.3 \pm 0.22^{b}$ & $1.0 \pm 0.30^{b}$ & $0.2 \pm 0.12^{b}$ \\
\hline
\end{tabular}

Values are expressed as mean \pm standard error of nine replicates; means followed by different superscript letter are significantly different based on DMRT $(P=0.05)$; SN - stem node, $\mathrm{CN}$ - cotyledonary node, $\mathrm{SE}$ - shoot explant

turing explants for a long time on a medium supplemented with TDZ resulted in the formation of twisted and dwarf shoots.

As shown by the results on a number of nodes per induced shoot, the regeneration ability of $G$. tenax shoot is highly dependent on the explant type and cytokinin concentrations (Table 3$)$. $\mathrm{CN}$ explants produced $(P<0.05)$ the highest number of nodes per shoot $(4.5 \pm 0.26)$ on $4.0 \mathrm{mg} / \mathrm{l} \mathrm{Kin-supplemented} \mathrm{medium.} \mathrm{SN} \mathrm{explants} \mathrm{produ-}$ ced the second average value $(4.3 \pm 0.21)$ of nodes on a medium supplemented with $3.0 \mathrm{mg} / 1 \mathrm{Kin}$ and lastly SE afforded $3.3 \pm 0.39$ nodes/shoot in a medium supplemented with $1.0 \mathrm{mg} / 1 \mathrm{BA}$. In general, Kin proved to be more effective than other cytokinins for increasing the average number of nodes per induced shoot (Table 3). Similar results on Kin effect for increasing the number of nodes were reported for Albizia falcataria (Widiyanto et al., 2008).

\section{Improving shoot multiplication of $G$. tenax}

\section{Subculture of explants onto the same media}

In this experiment, depending on the performance of shoot multiplication, only $\mathrm{CN}$ explant cultures were used for re-culturing. Moreover, TDZ cultures were excluded because all cultured explants formed heavy callusing. Hence, all CN cultures producing shoots were subcultured to fresh media containing the same cytokinins and their concentrations, in addition to a cytokinin-free me- 
Table 3. Effect of different cytokinins on the number of nodes per shoot formed on $G$. tenax explants after four weeks of in vitro culturing

\begin{tabular}{|c|c|c|c|c|}
\hline \multirow{2}{*}{\multicolumn{2}{|c|}{$\begin{array}{l}\text { Cytokinin } \\
{[\mathrm{mg} / \mathrm{l}]}\end{array}$}} & \multicolumn{3}{|c|}{ Explants types } \\
\hline & & \multirow{2}{*}{$\frac{\mathrm{SN}}{2.6 \pm 0.22^{\mathrm{bc}}}$} & \multirow{2}{*}{$\frac{\mathrm{CN}}{1.3 \pm 0.35^{\mathrm{cd}}}$} & \multirow{2}{*}{$\frac{\mathrm{SE}}{1.0 \pm 0.17^{\text {cd }}}$} \\
\hline & 0.0 & & & \\
\hline \multirow[t]{5}{*}{$\mathrm{BA}$} & 0.5 & $3.3 \pm 0.21^{b}$ & $2.2 \pm 0.42^{\mathrm{bc}}$ & $2.5 \pm 0.22^{b}$ \\
\hline & 1.0 & $3.7 \pm 0.21^{\mathrm{ab}}$ & $3.0 \pm 0.31^{\mathrm{bc}}$ & $3.3 \pm 0.39^{c}$ \\
\hline & 2.0 & $3.2 \pm 0.48^{\mathrm{bc}}$ & $2.7 \pm 0.60^{\mathrm{bc}}$ & $2.0 \pm 0.36^{\mathrm{cd}}$ \\
\hline & 3.0 & $3.2 \pm 0.60^{\mathrm{bc}}$ & $2.5 \pm 0.58^{\mathrm{bc}}$ & $1.8 \pm 0.31^{\mathrm{cd}}$ \\
\hline & 4.0 & $3.7 \pm 0.21^{\mathrm{ab}}$ & $2.3 \pm 0.45^{\mathrm{bc}}$ & $1.8 \pm 0.30^{\mathrm{cd}}$ \\
\hline \multirow[t]{5}{*}{ Kin } & 0.5 & $3.7 \pm 0.33^{\mathrm{ab}}$ & $2.2 \pm 0.17^{\mathrm{bc}}$ & $1.7 \pm 0.14^{\mathrm{cd}}$ \\
\hline & 1.0 & $3.3 \pm 0.33^{b}$ & $2.3 \pm 0.28^{\mathrm{bc}}$ & $1.7 \pm 0.19^{\text {cd }}$ \\
\hline & 2.0 & $3.8 \pm 0.48^{\mathrm{ab}}$ & $2.3 \pm 0.38^{\mathrm{bc}}$ & $2.0 \pm 0.19^{c}$ \\
\hline & 3.0 & $4.3 \pm 0.21^{\mathrm{ab}}$ & $3.7 \pm 0.19^{\mathrm{ab}}$ & $1.8 \pm 0.15^{\mathrm{cd}}$ \\
\hline & 4.0 & $3.5 \pm 0.50^{\mathrm{ab}}$ & $4.5 \pm 0.26^{\mathrm{a}}$ & $1.5 \pm 0.19^{\mathrm{cd}}$ \\
\hline \multirow[t]{5}{*}{$2 \mathrm{iP}$} & 0.5 & $2.7 \pm 0.21^{b c}$ & $1.5 \pm 0.19^{\mathrm{cd}}$ & $2.0 \pm 0.15^{\mathrm{c}}$ \\
\hline & 1.0 & $3.7 \pm 0.21^{\mathrm{ab}}$ & $1.8 \pm 0.30^{\mathrm{cd}}$ & $1.8 \pm 0.17^{\mathrm{cd}}$ \\
\hline & 2.0 & $2.5 \pm 0.34^{\mathrm{bc}}$ & $1.7 \pm 0.34^{\mathrm{cd}}$ & $1.8 \pm 0.13^{\mathrm{cd}}$ \\
\hline & 3.0 & $2.7 \pm 0.42^{b c}$ & $1.3 \pm 0.25^{\mathrm{cd}}$ & $1.7 \pm 0.19^{\mathrm{cd}}$ \\
\hline & 4.0 & $2.3 \pm 0.21^{\mathrm{bc}}$ & $0.8 \pm 0.22^{\text {cd }}$ & $1.7 \pm 0.14^{\mathrm{cd}}$ \\
\hline \multirow[t]{5}{*}{$\mathrm{TDZ}$} & 0.5 & $1.3 \pm 0.33^{\mathrm{cd}}$ & $1.6 \pm 0.26^{\mathrm{cd}}$ & $1.8 \pm 0.17^{\mathrm{cd}}$ \\
\hline & 1.0 & $0.7 \pm 0.21^{\mathrm{d}}$ & $1.2 \pm 0.15^{\mathrm{cd}}$ & $1.7 \pm 0.15^{\mathrm{cd}}$ \\
\hline & 2.0 & $0.5 \pm 0.22^{d}$ & $0.7 \pm 0.14^{d}$ & $1.3 \pm 0.13^{\mathrm{cd}}$ \\
\hline & 3.0 & $0.5 \pm 0.22^{d}$ & $0.5 \pm 0.14^{d}$ & $1.2 \pm 0.11^{\mathrm{cd}}$ \\
\hline & 4.0 & $0.5 \pm 0.22^{d}$ & $0.3 \pm 0.15^{d}$ & $1.0 \pm 0.19^{\mathrm{cd}}$ \\
\hline
\end{tabular}

Values are expressed as mean \pm standard error of nine replicates; means followed by different superscript letter are significantly different based on DMRT $(P=0.05)$; SN - stem node, $\mathrm{CN}$ - cotyledonary node, $\mathrm{SE}$ - shoot explant

dium, which was used as a control. The shoots clusters, after removing all callus and roots, were cultured for four weeks. The results showed that no new shoots produced, while all propagules formed excessive callus (Fig. 2). A declining number of shoots after subculturing into the same cytokinin supplemented media was reported for other plant species such as Hibiscus rosasinensis (Christensen et al., 2008). This decline could be because of the failure to rejuvenate or inadequate or excess concentration of plant regulatory compounds (Christensen et al., 2008). However, shoot subculturing $(P<0.05)$ significantly improved the number of nodes formed. BA at $2.0 \mathrm{mg} / 1$ stimulated the highest number of nodes with an average of $9.8 \pm 0.6$ nodes/shoot
(Fig. 2A). Moreover, Kin at $2.0 \mathrm{mg} / 1$ produced the second value ( 8.8 nodes) and $2 \mathrm{iP}$ the third value $(5.2 \pm 0.4$ nodes) per shoot. However, BA at $1.0 \mathrm{mg} / \mathrm{l}$ proved to be most effective for the elongation of shoots (6.48 $\pm 0.4 \mathrm{~cm}$ ) after subculturing. Furthermore, $2 \mathrm{iP}$ appeared a significantly less effectual cytokinin on shoot elongation with the maximum shoot length of $4.3 \pm 0.4 \mathrm{~cm}$ at $3.0 \mathrm{mg} / \mathrm{l}$ concentration (Fig. 2B).

Two general conclusions of subculturing $G$. tenax cytokinin-induced microshoots can be drawn from the experiments: 1) when the shoots were subcultured to a growth regulator-free MS medium, roots were effectively formed but no callusing was observed, and 2) when MS medium was supplemented with the same cytokinin; 


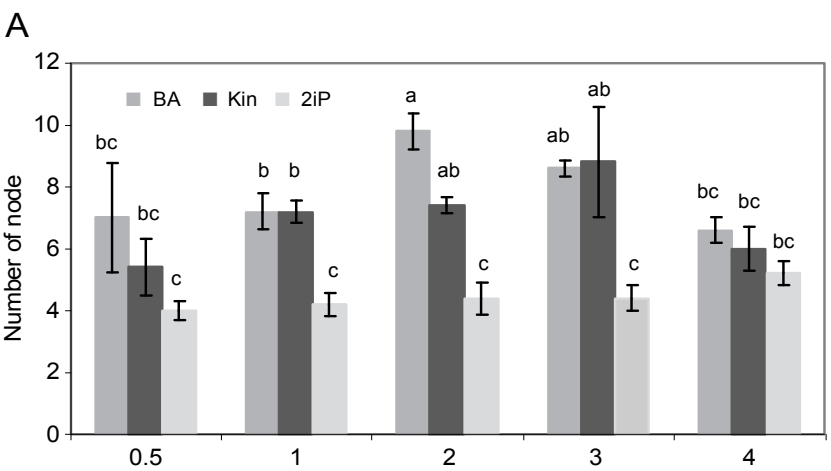

B

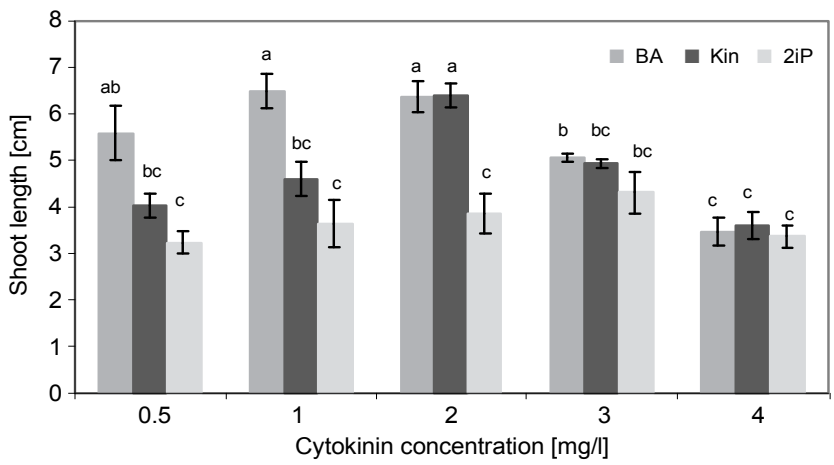

Fig. 2. Effect of subculture of shoot clumps of $G$. tenax into media of the same concentrations $(0.5-4.0)$ of BA, Kin or $2 \mathrm{iP}$ on A) nodes numbers and B) shoot length (cm) after four weeks of in vitro culturing; values represent the mean $\pm \mathrm{SE}$ of six replicates and different letters indicate significant differences between means based on DMRT $(P=0.05)$
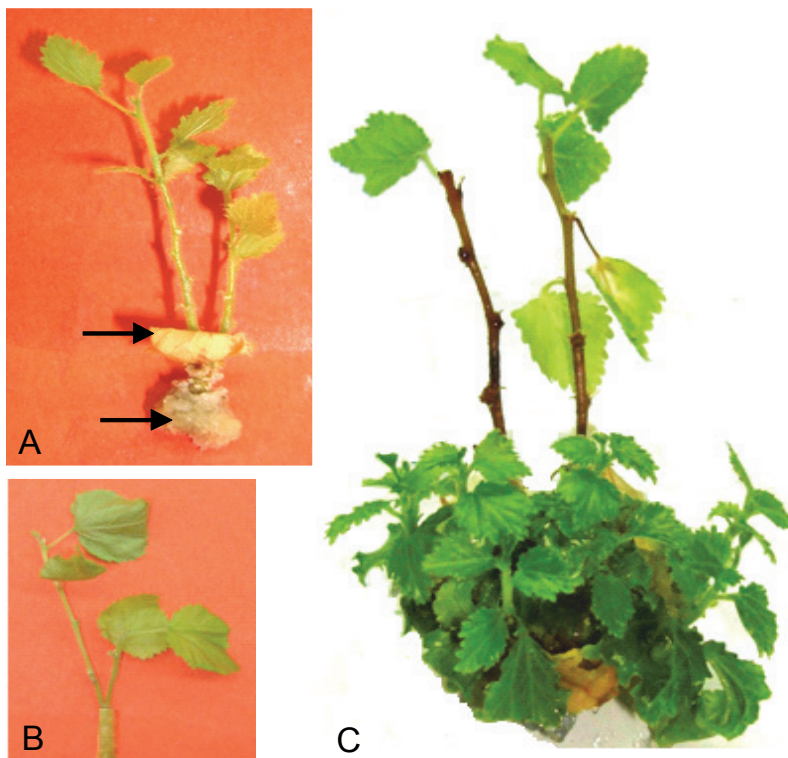

Fig. 3. Multiple shoots induction of $G$. tenax after subculture of $2 \mathrm{iP}$-induced shoots in $1 \mathrm{mg} / 1 \mathrm{BA}$ medium; A) 2-shoots induced in $3.0 \mathrm{mg} / 12 \mathrm{iP}$ with callus and cotyledons attached (arrows); B) prepared 2-shoot explant; C) multiple shoots induction after culture for four weeks in $1.0 \mathrm{mg} / \mathrm{l} \mathrm{BA}$

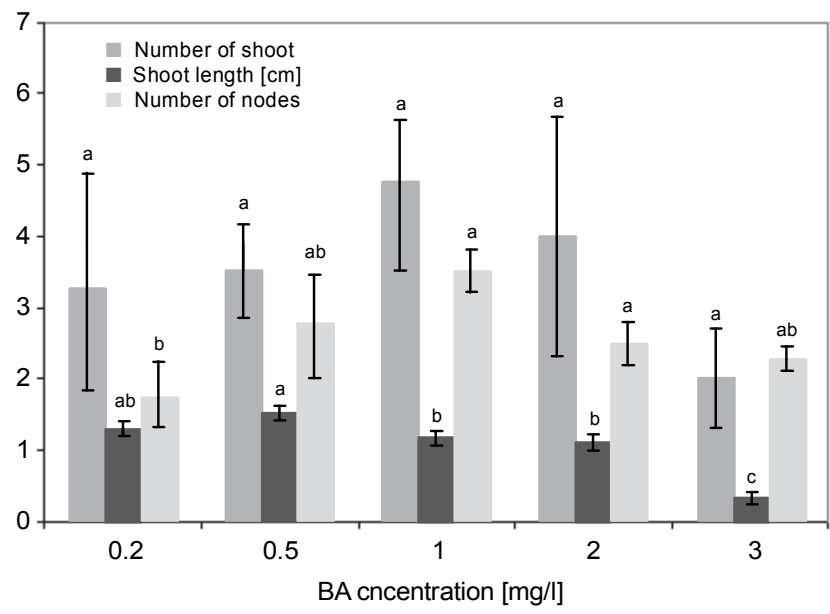

Fig. 4. Effect of subculture 2iP-induced shoot clumps of $G$. tenax into media with different concentrations of BA $(0.2-3.0 \mathrm{mg} / \mathrm{l})$ on number of shoots, number of nodes, and shoot length $(\mathrm{cm})$ after four weeks of in vitro culturing; values represent the mean $\pm \mathrm{SE}$ of six replicates; different letters indicate significant differences between BA concentrations means based on DMRT $(P=0.05)$

the shoot length, the number of nodes, and callogenesis were all enhanced, and roots were induced. Note that after subculturing, BA stimulated shoot development with high efficiency (elongation and number of nodes); however, $2 \mathrm{iP}$ prompted the lowest shoot length and the smallest number of nodes, which is opposite to the results obtained before subculturing (Fig. 2).

\section{Subculture of 2iP-treated shoots to BA-amended media}

In this experiment, $\mathrm{CNs}$ with induced clumps of two shoots on an average (Fig. 3A) were removed from the primary medium (MS $+3.0 \mathrm{mg} / 12 \mathrm{iP}$ ). The 2-shoot explants were prepared by removing all existing callus (Fig. 3B), which were then transferred to an MS medium containing BA at $0.0-3.0 \mathrm{mg} / 1$ concentrations. The results showed that $B A$ at $1.0 \mathrm{mg} / 1$ induced the maximum new shoots per explant with an average of 4.8 \pm 0.9 (Fig. 3C and Fig. 4). This indicated that shoots cluster of $G$. tenax transferred from the 2iP-medium to the BA-medium formed more axillary shoots than continuously growing shoots on $2 \mathrm{iP}$ or $\mathrm{BA}$ media. $\mathrm{CN}$ explants produced an average of $2.8 \pm 0.2$ and $2.5 \pm 0.2$ shoots on media separately supplemented with $2 \mathrm{iP}$ $3.0 \mathrm{mg} / 1$ or BA $2.0 \mathrm{mg} / 1$, respectively (Table 1 ). Furthermore, the variation on the effects of BA concentrations on shoot growth between primary and secondary media was reported for Jatropha curcas (Sujatha et al., 2005). 

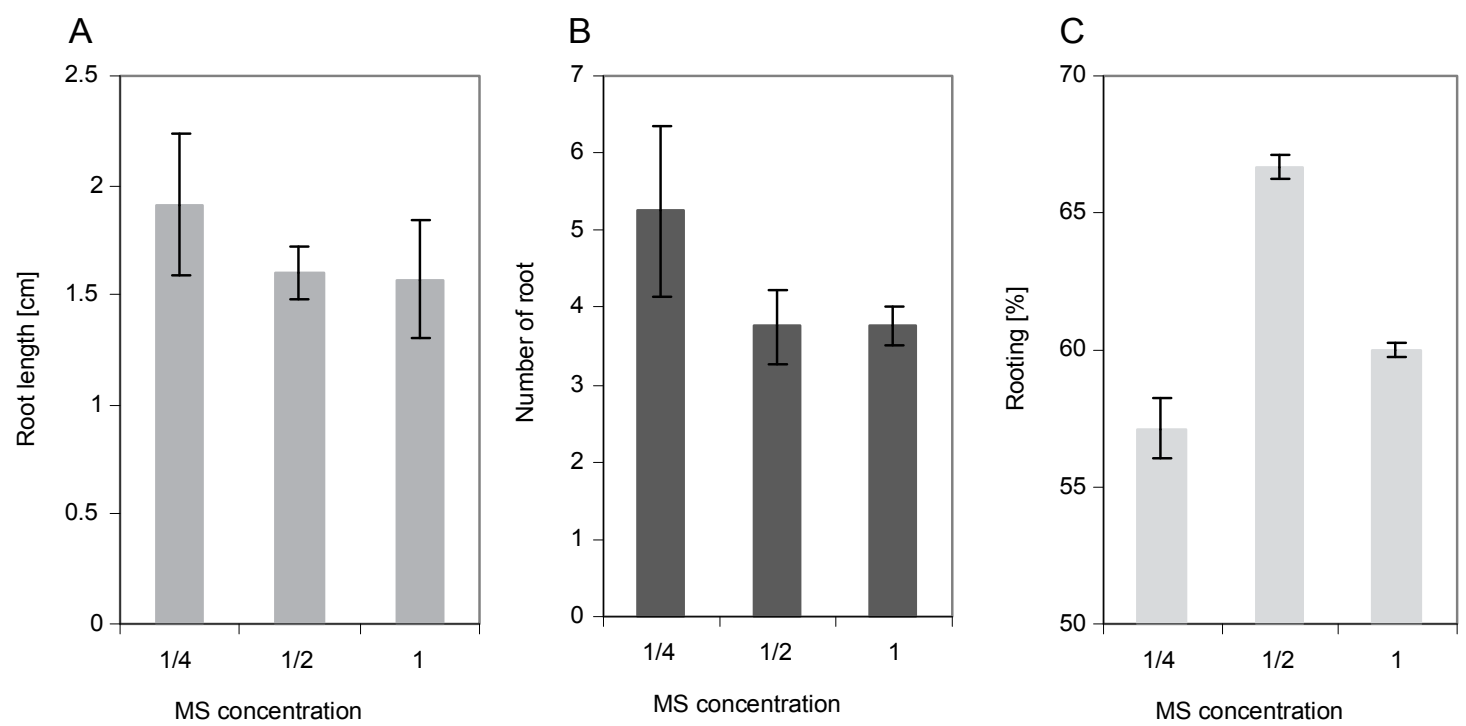

Fig. 5. Effect of different MS medium strengths $(1 / 4,1 / 2$, and 1$)$ on the in vitro rooting of $G$. tenax shoots after four weeks of culturing; A) average number of root per shoot; B) average root length; C) rooting percentage; values represent the mean $\pm \mathrm{SE}$ of six replicates; different letters indicate significant differences between MS concentrations means based on DMRT $(P=0.05)$
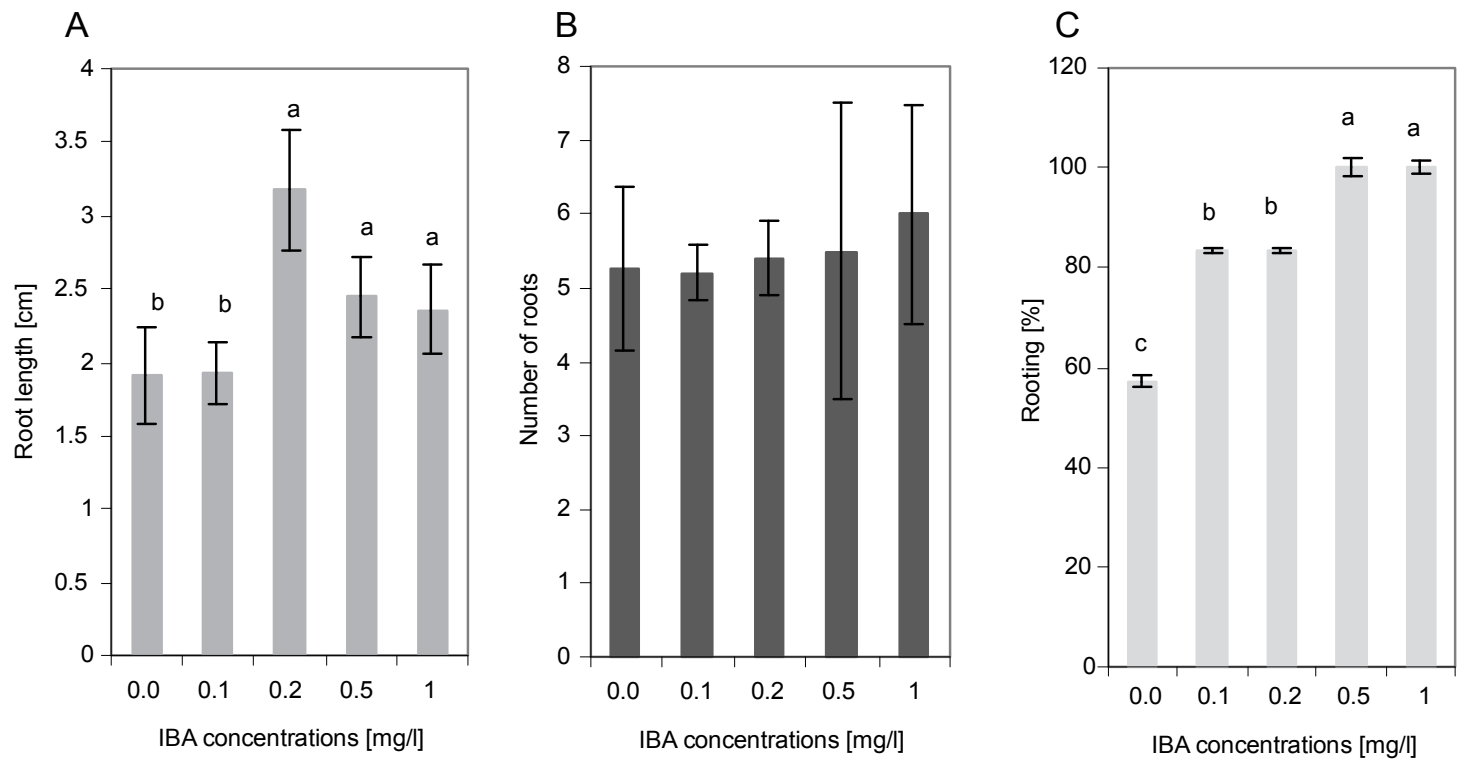

Fig. 6. Effect of different IBA concentrations $(0.0-1.0 \mathrm{mg} / \mathrm{l})$ supplemented in $1 / 4 \mathrm{MS}$ strengths on the in vitro rooting of G. tenax shoots after four weeks of in vitro culture; A) average root length; B) average number of root per shoot; and C) rooting percentage; values represent the mean \pm SE of six replicates; different letters indicate significant differences between IBA concentrations means based on DMRT $(P=0.05)$

The length of shoots and the number of nodes of newly formed shoots were reduced from that of the primary 2 -shoot explants with a maximum length of $1.5 \pm 0.1 \mathrm{~cm}$ and $3.5 \pm 0.3$ nodes acquired for a $0.5 \mathrm{mg} / \mathrm{l} \mathrm{BA-fortified}$ medium (Fig. 4). Moreover, new shoots appeared to be thinner in diameter and the leaves were smaller in size (Fig. 3C). The application of two different multiplication media in alternate routes noticeably enhanced the rate of shoot multiplication of $G$. tenax. A similar strategy for the subculturing of multiple shoots induced from $\mathrm{CNs}$ on BA medium for proliferation purposes has been reported for many species such as Jatropha curcas (Sujatha et al., 2005), Pterocarpus marsupium (Husain et al., 2007), and Cassia sophera (Parveen and Shahzad, 2010). 


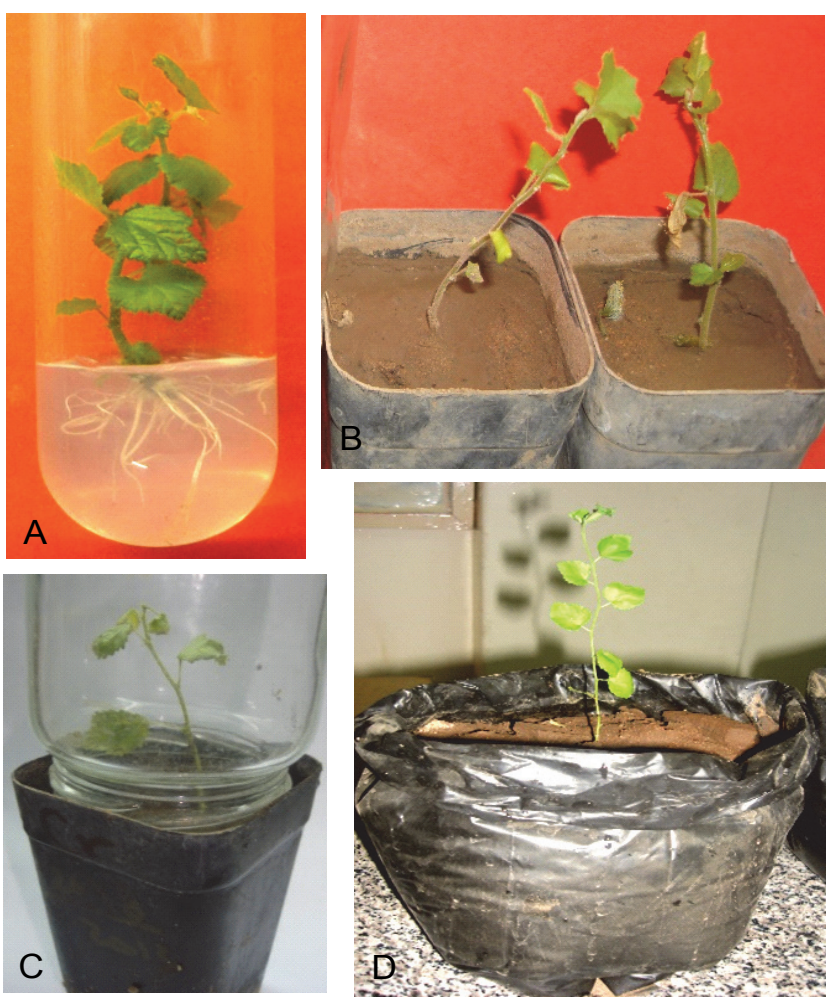

Fig. 7. In vitro rooting and acclimatization of $G$. tenax: A) in vitro rooting of shoots after four weeks of culturing on $1 / 4 \mathrm{MS}$ supplemented with $1.0 \mathrm{mg} / \mathrm{lBA}$; B) plantlets grown in pots in a mixture of silt: sand $(1: 1 ; \mathrm{v} / \mathrm{v})$ soil under room conditions covered with a glass vessel for 3 weeks; C) acclimatized plantlets after three weeks in pots at room temperature; and

D) acclimatized plant under greenhouse conditions

\section{In vitro rooting}

\section{Effect of MS medium strength on the in vitro rooting} of G. tenax shoots

All tested MS medium strengths supported root induction within two weeks of transferring shoots (induced by $1.0 \mathrm{mg} / 1 \mathrm{BA}$ ) to the appropriate media (Fig. 5). In a $1 / 4$ strength MS medium, shoots produced significantly $(P<0.05)$ the longest $(1.9 \pm 1.0 \mathrm{~cm})$ roots (Fig. 5A) and the highest number of roots $(5.3 \pm 1.1)$ per shoot (Fig. 5B). In an earlier study, Ali and Abd Alla (2003) found that $G$. tenax shoots cultured in full MS produced longer roots $(2.8 \mathrm{~cm})$ and a higher number of roots (9.1) compared to full MS medium supplemented with IBA. Moreover, Daffalla et al. (2016) reported the in vitro rooting of $G$. tenax shoots in an auxin-free MS medium; however, no rooting measurements were provided. In our research, $66.7 \%$ of the shoots cultured in $1 / 2$-strength MS were rooted, compared to $60 \%$ and $57.1 \%$ in 1 - and $1 / 4$-strength MS, respectively (Fig. 5C).
A similar result for root induction in a medium free from auxins has been reported for Cassia sophera with 65\% and $42.3 \%$ rooting of shoots in $1 / 2 \mathrm{MS}$ and full MS media, respectively (Parveen and Shahzad, 2010). Spontaneous rhizogenesis in an auxin-free medium was observed in shoot cultures of Hibiscus rosasinensis, a member of the Malvaceae family (Christensen et al., 2008 ). The rapid rooting of in vitro grown shoots in an auxin-free medium is because of the level of auxin content in the plant tissue, which is adequate for root formation (Minocha, 1987). No callus was observed in shoots cultured on 1/4 MS medium, whereas moderate and massive callus formation were observed at the junctions of roots and shoots in the cultures grown on $1 / 2$ MS and full MS, respectively. The drop in the callus formation at the basal end of the shoots with a decreasing MS strength could be attributed to the reduction of sucrose in the media. Alternatively, a reduction in nutrients content might make the medium unsuitable for callus development. Generally, using a medium with reduced salt strength for rooting is preferred for increasing the rooting frequency as was reported for many tree species such as Givotia rottleriformis (Samuel et al., 2009) and Cassia sophera (Parveen and Shahzad, 2010).

\section{Effect of IBA on the in vitro rooting of $G$. tenax shoots}

IBA was preferred for the in vitro root formation due to its higher effectiveness than that of other auxins in many tree species such as Givotia rottleriformis (Samuel et al., 2009), Cassia sophera (Parveen and Shahzad, 2010), and Clitoria ternatea (Mukhtar et al., 2012). IBA $(0.0-1.0 \mathrm{mg} / \mathrm{l})$ was supplemented to $1 / 4$-strength MS medium, which was considered optimal for rhizogenesis (Fig. 5). Significantly $(P<0.05)$ long roots $(3.2$ $\pm 0.4 \mathrm{~cm})$ were achieved in an IBA-augmented medium of $0.2 \mathrm{mg} / \mathrm{l}$ (Fig. $6 \mathrm{~A}$ ). However, the maximum number of roots per shoot $(6 \pm 1.5)$ - Figure $6 \mathrm{~B}$ was formed in the presence of $1.0 \mathrm{mg} / 1 \mathrm{IBA}$. In a previous work on the rooting of G. tenax, Ali and Abd Alla (2003) reported that the maximum root length $(1.5 \mathrm{~cm})$ and the highest number of roots (8) were induced by $0.5 \mathrm{mg} / \mathrm{l}$ IBA. Moreover, increasing the IBA concentration to 0.5 and $1.0 \mathrm{mg} / 1(P<0.05)$ significantly enhanced the rooting frequency to $100 \%$ in both concentrations (Fig. $6 \mathrm{C}$ ). Generally, the roots that were developed were healthy but varied in morphology, e.g., hairy-twisted roots were produced in lower IBA concentrations $(0.0-0.2 \mathrm{mg} / \mathrm{l})$ and 
thick roots having well-developed secondary branches were formed at higher IBA concentrations $(0.5$ and $1.0 \mathrm{mg} / \mathrm{l})$ (Fig. 7A). Similar results on the variation of root morphology depending on IBA concentrations have been reported for Bixa orellana (Joseph et al., 2011).

\section{Acclimatization of in vitro propagated G. tenax plantlets}

The rooted regenerants of $G$. tenax (Fig. 7A) were transferred to soil pots and $~ 90 \%$ (69/77 plants) of them survived for 1 month in plastic pots (Fig. 7B and Fig. 7C). Each plantlet with roots accompanied by callus failed to survive and died after one week of acclimatization ( $10 \%$ of regenerants). The survived plantlets were successfully transferred to greenhouse conditions with a survival rate of up to $75 \%$ (52/69 plants) for one month (Fig. 7D). A similar high survival percentage of micropropagated plantlets has been reported for other trees such as $75 \%$ for Givotia rottleriformis (Samuel et al., 2012), $88 \%$ for Clitoria ternatea, and $90 \%$ for Cassia sophera (Parveen and Shahzad, 2010). The plantlets easily acclimatized without morphological variations.

\section{Conclusions}

$\mathrm{CN}$ explants cultured in an MS medium supplemented with $3.0 \mathrm{mg} / 12 \mathrm{iP}$ produced an average of 2.8 shoots. To improve shoot multiplication, we developed a twostep procedure. The propagules of 2 -shoots induced on a $3.0 \mathrm{mg} / 12 \mathrm{iP}$ primary medium were subcultured onto a secondary medium containing $1.0 \mathrm{mg} / \mathrm{l} \mathrm{BA}$. This procedure enhanced the number of shoots to five shoots per explant. The in vitro rooting of shoots was accomplished with $100 \%$ frequency in $1 / 4$-strength MS medium supplemented with $1.0 \mathrm{mg} / 1 \mathrm{IBA}$. We acclimatized 52 out of 77 plantlets, i.e., a survival rate of $67 \%$.

\section{References}

Aboagarib E.A.A., Yang R., Hua X. (2015) Physicochemical, nutritional, and functional characteristics of seeds, peel and pulp of Grewia tenax (Forssk) Fiori fruits. Trop. J. Pharm. Res. 14 (12): 2247-254.

Ali Y.H., Abd Alla M.A. (2003) Vegetative propagation of Grewia tenax (Forsk.) Fiori by stem cuttings and micropropagation. Sudan J. Basic Sci. Section B Biol. Sci. 3.

Biswas B., Joshee N., Yadav A., Yadav A.K. (2005) In vitro propagation and somatic embryogenesis in Phalsa. Hort. Sci. 40: 1104.

Christensen B., Sriskandarajah S., Serek, M., Müller R. (2008) In vitro culture of Hibiscus rosa-sinensis L.: Influence of iron, calcium and BAP on establishment and multiplication. Plant Cell Tissue Organ Cult. 93: 151-161.

Daffalla H.M., Elsheikh A.M., Ali H.A., Khalfala M.M. (2016) In vitro seed germination and node culture of the nutraceutical plant Grewia tenax. Environ. Exp. Biol. 14: 75-81.

El Ghazali G.E.B., El Tohami M.S., El Egami A.A.B., Abdalla W.S., Mohammed M.G. (1997) Medicinal plants of the Sudan, part IV: Northern Kordofan. Omdurman Islamic University Printing and Publishing House, Khartoum, Sudan.

Elhassan G.O.M., Yagi S.M. (2010) Nutritional Composition of Grewia species (Grewia tenax (Forsk.) Fiori, G. flavescens Juss and G. villosa Willd) fruits. Adv. J. Food Sci. Technol. 2(3): 159-162.

Elkhalifa K.F., Mahmoud S.M. (1999) Establishment of Grewia tenax (Forssk.) Fiori from seeds and stem cuttings in the nursery. Arab Gulf J. Sci. Res. 17(1): 85-94.

El Tahir B.A., Gebauer J. (2004) Non-timber forest products: Opportunities and constraints for poverty reduction in the Nuba Mountains, South Kordofan, Sudan. Conference on International Agricultural Research for Development. Deutscher Tropentag, October 5-7, 2004, Berlin, Germany.

El-Siddig K., Gebauer J., Inanaga S., Ludders P. (2005) Auxin effects on rooting of stem cuttings of Grewia tenax: a potential alleviator of iron-deficiency anemia in the $\mathrm{Su}$ dan. The Global Food and Product Chain - Dynamics, Innovations, Conflicts, Strategies. October 11-13, 2005, Deutscher, Tropentag, Hohenheim, Germany.

Gebauer J., El-Siddig K., El Tahir B.A., Salih A.A., Ebert G., Hammer K. (2007) Exploiting the potential of indigenous fruit trees: Grewia tenax (Forssk.) Fiori in Sudan. Genet. Resour. Crop Evol. 54: 1701-1708.

HCENR (2000) First national report on the implementation of the convention on biological diversity. The Higher Council for Environment and Natural Resources (HCENR), Government of the Republic of the Sudan, Ministry of Environment and Tourism, Khartoum, Sudan.

Husain M.K., Anis M., Shahzad A. (2007) In vitro propagation of Indian Kino (Pterocarpus marsupium Roxb.) using thidiazuron. In Vitro Cell. Dev. Biol. Plant. 43: 59-64.

Ishii K., Kambou S. (2007) In vitro culture of an African multipurpose tree species: Adansonia digitata L. Propag. Ornam. Plants. 7: 62-67.

Jana S., Sivanesan I., Jeong B.R. (2013) Effect of cytokinins on in vitro multiplication of Sophora tonkinensis. Asian Pac. J. Trop. Biomed. 3: 549-553.

Joseph N., Siril E.A., Nair G.M. (2011) An efficient in vitro propagation methodology for Annatto (Bixa orellana L.). Physiol. Mol. Biol. Plants. 17: 263-270.

Khalafalla M.M., Daffalla H.M. (2008) In vitro micropropagation and micrografting of gum Arabic tree [Acacia senegal (L.) Wild]. Int. J. Sustain. Crop Prod. 3: 19-27.

Khemis F., Ghoul-Mazgar S., Meshtaghie A.A., Saidane D. (2006) Study of the effect of aqueous extract of Grewia tenax fruit on iron absorption by everted gut sac. J. Ethnopharmacol. 103: 90-98. 
Kumawat R.N., Misra A.K., Mounir L., Mahajan S.S., Venkatesan K. (2017) Seed germination behaviour as influenced by physical and chemical treatments in Grewia tenax (Forssk.). Range Manag. Agrofor. 38(1): 134-138.

Minocha S.C. (1987) Plant growth regulators and morphogenesis in cell and tissue culture of forest trees. [in:] Cell and tissue culture in forestry, vol. 1. Ed. Bonga J.M., Durjan D.J. Martinus Nijhoff Publishers, Dordrecht, the Netherlands: $50-66$.

Mukhtar S., Ahmad N., Khan M.I., Anis M., Aref I.M. (2012) Influencing micropropagation in Clitoria ternatea L. through the manipulation of TDZ levels and use of different explant types. Physiol. Mol. Biol. Plants. 18: 381-386.

Murashige T., Skoog F. (1962) A revised medium for rapid growth and bioassays with tobacco tissue cultures. Physiol. Plant. 15: 473-497.

Parveen S., Shahzad A. (2010) TDZ-induced high frequency shoot regeneration in Cassia sophera Linn. via cotyledonary node explants. Physiol. Mol. Biol. Plants. 16: 201-206.

Sahoo K.P., Kasera P.K. (2012) Improvement in seed germination of Grewia tenax (Forsk.) Fiori by providing different nitrate pretreatments. Ann. Arid Zone 51(2): 141-142.

Saleem N.A., Mohamed K.A.A., El Nour M. (2012) Different growth characteristics of Grewia mollis, Grewia tenax and Grewia villosa under nursery and field conditions. J. Life Sci. 6: 1016-1024.
Samuel K., Debashish D., Madhumita B., Padmaja G., Prasad S.R., Bhaskara V., Murthy R., Rao P.S. (2009) In vitro germination and micropropagation of Givotia rottleriformis Griff. In Vitro Cell. Dev. Biol. Plant. 45: 466-473.

Sharma N., Patni V. (2012) Grewia tenax (Frosk.) Fiori. a traditional medicinal plant with enormous economic prospectives. Asian J. Pharm. Sci. 5: 28-32.

Sujatha M., Makkar H.P.S., Becker K. (2005) Shoot bud proliferation from axillary nodes and leaf sections of non-toxic Jatropha curcas L. Plant Growth Regul. 47: 83-90.

Sohail M., Saied A.S., Gebauer J., Buerkert A. (2015) Seed dormancy alleviation of Grewia tenax (Forssk.): a wild fruit tree species of Pakistan. Pak. J. Bot. 47(2): 417-420.

Van Staden J., Zazimalova E., George E.F. (2008) Chapter 6: Plant growth regulators II: Cytokinins, their analogues and antagonists. [in:] Plant propagation by tissue culture, vol. 1. Ed. George E.F., Hall M.A., De Klerk G. Springer, Dordrecht, the Netherlands: 205-226.

Widiyanto S.N., Sari M.D., Irwanto R.R. (2008) Effect of cytokinins and carbenicillin on in vitro axillary-shoot growth of Albizia (Albizia falcataria (L.) Fosberg). J. Matem. Sains 13: 43-49. 